\title{
Magnetism in $\mathrm{Ca}_{2} \mathrm{CoOsO}_{6}$ and $\mathrm{Ca}_{2} \mathrm{NiOsO}_{6}$ : Unraveling the mystery of superexchange interactions between $3 \mathrm{~d}$ and $5 \mathrm{~d}$ ions
}

\author{
Ryan Morrow, ${ }^{\dagger}$ Kartik Samanta, ${ }^{\ddagger}$ Tanusri Saha Dasgupta, ${ }^{*}$ Jie Xiong, ${ }^{\dagger}$ John W. Freeland, ${ }^{\S}$ Daniel \\ Haskel, $^{\S}$ and Patrick M. Woodward ${ }^{\dagger *}$ \\ ${ }^{\dagger}$ Department of Chemistry and Biochemistry, The Ohio State University, Columbus, Ohio 43210-1185, USA \\ ${ }^{\ddagger}$ Department of Condensed Matter Physics and Materials Sciences, S. N. Bose National Centre for Basic Sciences, JD \\ Block, Sector III, Salt Late, Kolkata 700098, India
}

${ }^{\S}$ Advanced Photon Source, Argonne National Laboratory, 970o Cass Avenue, Argonne, Illinois 6o439, USA

\section{SUPPORTING INFORMATION}

Table S1 lists the expected moments for the free ions of osmium in three different oxidation states, as well as for $\mathrm{Co}^{2+}$ and $\mathrm{Ni}^{2+}$. Values are given for effective moments in the weak-field limit, appropriate for ions in the paramagnetic state, and the strong field limit, appropriate for measurements taken when a material is magnetically ordered, such as neutron powder diffraction and X-ray magnetic circular dichroism. These values are given both under the assumptions of a spin only contribution (S) and Russell Saunders coupling (J).

Table S1: Quantum numbers and local moments for free transition metal ions of interest in both the weak and strong field cases. The presence of ligands introducing crystal field splitting will modify these values.

\begin{tabular}{|c|c|c|c|c|c|c|c|c|c|}
\hline & & \multicolumn{3}{|c|}{ Free ion values } & & \multicolumn{2}{c|}{$\begin{array}{c}\text { Weak field effective } \\
\text { moments }\end{array}$} & \multicolumn{2}{c|}{ Strong field moments } \\
\hline Ion & $\begin{array}{c}\text { electron } \\
\text { config. }\end{array}$ & $\mathbf{S}$ & $\mathrm{L}$ & $\mathrm{J}$ & $\begin{array}{c}\text { Term } \\
\text { symbol }\end{array}$ & $\boldsymbol{\mu}_{\text {eff }}(\mathrm{J})$ & $\begin{array}{c}\mu_{\text {eff }} \text { (spin } \\
\text { only) }\end{array}$ & $\begin{array}{c}\boldsymbol{\mu}(\mathrm{J}) \\
\boldsymbol{\mu}(\mathbf{s p i n} \\
\text { only) }\end{array}$ \\
\hline $\mathrm{Os}(\mathrm{VII})$ & $\mathrm{d}^{1}$ & $1 / 2$ & 2 & $3 / 2$ & ${ }^{2} \mathrm{D}_{3 / 2}$ & $1.55 \mu_{\mathrm{B}}$ & $1.73 \mu_{\mathrm{B}}$ & $1.20 \mu_{\mathrm{B}}$ & $1 \mu_{\mathrm{B}}$ \\
\hline $\mathrm{Os}(\mathrm{VI})$ & $\mathrm{d}^{2}$ & 1 & 3 & 2 & ${ }^{3} \mathrm{~F}_{2}$ & $1.63 \mu_{\mathrm{B}}$ & $2.83 \mu_{\mathrm{B}}$ & $1.33 \mu_{\mathrm{B}}$ & $2 \mu_{\mathrm{B}}$ \\
\hline $\mathrm{Os}(\mathrm{V})$ & $\mathrm{d}^{3}$ & $3 / 2$ & 3 & $3 / 2$ & ${ }^{4} \mathrm{~F}_{3 / 2}$ & $0.77 \mu_{\mathrm{B}}$ & $3.88 \mu_{\mathrm{B}}$ & $0.60 \mu_{\mathrm{B}}$ & $3 \mu_{\mathrm{B}}$ \\
\hline $\mathrm{Co}(\mathrm{II})$ & $\mathrm{HS} \mathrm{d}^{7}$ & $3 / 2$ & 3 & $9 / 2$ & ${ }^{4} \mathrm{~F}_{9 / 2}$ & $6.63 \mu_{\mathrm{B}}$ & $3.88 \mu_{\mathrm{B}}$ & $6 \mu_{\mathrm{B}}$ & $3 \mu_{\mathrm{B}}$ \\
\hline $\mathrm{Ni}(\mathrm{II})$ & $\mathrm{d}^{8}$ & 1 & 3 & 4 & ${ }^{3} \mathrm{~F}_{4}$ & $5.59 \mu_{\mathrm{B}}$ & $2.83 \mu_{\mathrm{B}}$ & $5 \mu_{\mathrm{B}}$ & $2 \mu_{\mathrm{B}}$ \\
\hline
\end{tabular}


Table S2 gives the magnetic behavior of a select variety of double perovskites containing a single magnetic ion. Double perovskites containing only a $3 \mathrm{~d}$ magnetic ion typically order as type II antiferromagnets due to dominant next nearest neighbor interactions, such as the examples containing $\mathrm{Co}(\mathrm{II})$ and $\mathrm{Ni}(\mathrm{II})$. Double perovskites containing a single $4 \mathrm{~d}$ or $5 \mathrm{~d}$ magnetic ion typically form a type I antiferromagnetic structure due to dominant nearest neighbor interactions. While many cases involving $\mathrm{Os}(\mathrm{VI})$ are either spin glass or have an antiferromagnetic structure which is yet to be determined due to small moments, the Os(V) containing compounds consistently form type I antiferromagnets.

Table S2: Magnetic properties of double perovskites containing either $\mathrm{Co}, \mathrm{Ni}$ or Os.

\begin{tabular}{|c|c|c|c|c|c|c|}
\hline Compound & $\begin{array}{l}\text { Space } \\
\text { Group }\end{array}$ & Magnetic behavior ${ }^{\dagger}$ & $\begin{array}{l}\text { Neutron } \\
\text { moment }\end{array}$ & $\begin{array}{c}\text { Effective } \\
\text { moment }\left(\mu_{B}\right)\end{array}$ & $\begin{array}{c}\text { Weiss } \\
\text { constant }(\theta)\end{array}$ & Reference \\
\hline \multicolumn{7}{|l|}{$\operatorname{Co}(I I)-d^{7}$} \\
\hline $\mathrm{Sr}_{2} \mathrm{CoWO}_{6}$ & $\mathrm{P} 2{ }_{1} / \mathrm{n}^{*}$ & Type II AFM, $T_{N}=24 \mathrm{~K}$ & $2.35(3) \mu_{B}$ & $5.2 \mu_{\mathrm{B}}$ & $-62 \mathrm{~K}$ & 1,2 \\
\hline $\mathrm{Ca}_{2} \mathrm{CoWO}_{6}$ & $\mathrm{P} 2_{1} / \mathrm{n}$ & Type II AFM, $T_{N}=36 \mathrm{~K}$ & $3.00(4) \mu_{\mathrm{B}}$ & $5.1 \mu_{\mathrm{B}}$ & $-68 K$ & 1,3 \\
\hline \multicolumn{7}{|l|}{$\mathrm{Ni}(\mathrm{II})-\mathrm{d}^{8}$} \\
\hline $\mathrm{Sr}_{2} \mathrm{NiWO}_{6}$ & $14 / \mathrm{m}$ & Type II AFM, $T_{\mathrm{N}}=54 \mathrm{~K}$ & -- & $3.3 \mu_{\mathrm{B}}$ & $-117 \mathrm{~K}$ & 4 \\
\hline $\mathrm{Ca}_{2} \mathrm{NiWO}_{6}$ & $\mathrm{P} 2_{1} / \mathrm{n}$ & Type II AFM, $T_{N}=56 \mathrm{~K}$ & $1.94(2) \mu_{B}$ & $3.2 \mu_{\mathrm{B}}$ & $-100 \mathrm{~K}$ & 2,5 \\
\hline \multicolumn{7}{|l|}{$O s(V I I)-d^{1}$} \\
\hline $\mathrm{Ba}_{2} \mathrm{LiOsO}_{6}$ & $\mathrm{Fm}-3 \mathrm{~m}$ & $\mathrm{AFM}, T_{\mathrm{N}}=8 \mathrm{~K}$ & --- & $0.73 \mu_{\mathrm{B}}$ & $-40 \mathrm{~K}$ & 6,7 \\
\hline $\mathrm{Ba}_{2} \mathrm{NaOsO}_{6}$ & $\mathrm{Fm}-3 \mathrm{~m}$ & $\mathrm{FM}, T_{C}=6.8 \mathrm{~K}$ & -- & $0.67 \mu_{\mathrm{B}}$ & $-32 \mathrm{~K}$ & $6-8$ \\
\hline \multicolumn{7}{|l|}{$O s(V I)-d^{2}$} \\
\hline $\mathrm{Ba}_{2} \mathrm{CaOsO}_{6}$ & $\mathrm{Fm}-3 \mathrm{~m}$ & $\mathrm{AFM}, T_{\mathrm{N}}=50 \mathrm{~K}$ & $\leq 0.2 \mu_{\mathrm{B}}$ & $1.64 \mu_{\mathrm{B}}$ & $-156 \mathrm{~K}$ & 9 \\
\hline $\mathrm{Ca}_{2} \mathrm{CaOsO}_{6}$ & $\mathrm{P} 2_{1} / \mathrm{n}$ & $\mathrm{AFM}, T_{\mathrm{N}}=50 \mathrm{~K}$ & --- & $1.99 \mu_{\mathrm{B}}$ & $-151 K$ & 10 \\
\hline $\mathrm{Sr}_{2} \mathrm{MgOsO}_{6}$ & $14 / \mathrm{m}$ & AFM, $T_{N}=110 \mathrm{~K}$ & --- & $1.87 \mu_{\mathrm{B}}$ & $-347 \mathrm{~K}$ & 11,12 \\
\hline $\mathrm{Ca}_{2} \mathrm{MgOsO}_{6}$ & $\mathrm{P} 2_{1} / \mathrm{n}$ & $\mathrm{SG}, T_{\mathrm{f}}=19 \mathrm{~K}$ & -- & $1.87 \mu_{\mathrm{B}}$ & $-71 K$ & 12 \\
\hline \multicolumn{7}{|l|}{$O s(V)-d^{3}$} \\
\hline $\mathrm{Ba}_{2} \mathrm{YOsO}_{6}$ & $\mathrm{Fm}-3 \mathrm{~m}$ & Type I AFM, $T_{N}=69 \mathrm{~K}$ & $1.65(6) \mu_{\mathrm{B}}$ & $3.93 \mu_{\mathrm{B}}$ & $-717 \mathrm{~K}$ & 13 \\
\hline $\mathrm{Sr}_{2} \mathrm{ScOsO}_{6}$ & $\mathrm{P} 2_{1} / \mathrm{n}$ & Type I AFM, $T_{\mathrm{N}}=92 \mathrm{~K}$ & $1.6(1) \mu_{\mathrm{B}}$ & $3.18 \mu_{\mathrm{B}}$ & $-677 \mathrm{~K}$ & 14,15 \\
\hline $\mathrm{Sr}_{2} \operatorname{lnOsO}{ }_{6}$ & $\mathrm{P} 2_{1} / \mathrm{n}$ & Type I AFM, $T_{N}=26 \mathrm{~K}$ & $1.77(6) \mu_{\mathrm{B}}$ & $3.25 \mu_{\mathrm{B}}$ & $-107 \mathrm{~K}$ & 15 \\
\hline $\mathrm{Sr}_{2} \mathrm{YOsO}_{6}$ & $\mathrm{P} 22_{1} / \mathrm{n}$ & Type I AFM, $T_{N}=53 \mathrm{~K}$ & $1.91(3) \mu_{\mathrm{B}}$ & $3.42 \mu_{\mathrm{B}}$ & $-319 \mathrm{~K}$ & 15 \\
\hline
\end{tabular}


Figure S1 portrays the aforementioned type I and type II antiferromagnetic structures on a pseudo face centered cubic sublattice formed on the double perovskite lattice with a single magnetic B cation. The pathways of the nearest neighbor (NN) and next nearest neighbor (NNN) exchange interactions that are dominant in each structure type are shown on the corresponding structure.

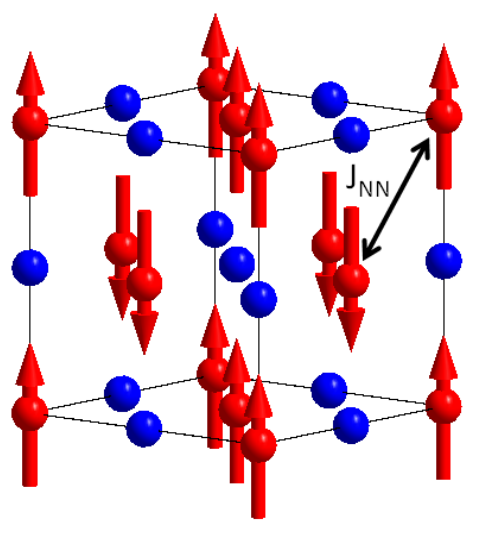

Type I Antiferromagnetism

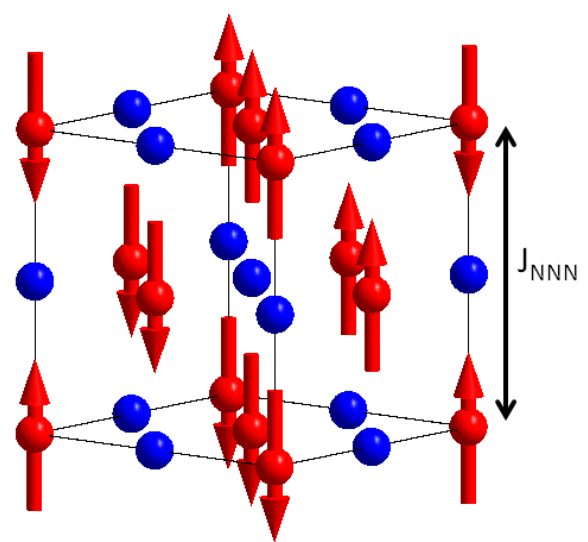

Type II Antiferromagnetism

Figure S1 - Illustrations of type I and type II AFM ordering of a face centered cubic magnetic sublattice. The non-magnetic $\mathrm{M}$ ions in an $\mathrm{A}_{2} \mathrm{MM}^{\prime} \mathrm{O}_{6}$ double perovskite are represented with blue spheres, while the A-site and oxygen ions have been omitted for clarity. The black arrow shows the exchange pathway of the nearest neighbor (NN) and next nearest neighbor (NNN) interactions which dominate in the type I and type II configurations, respectively. 
Figure $\mathrm{S} 2$ shows the total density of states for $\mathrm{Ca}_{2} \mathrm{CoOsO}_{6}$ and $\mathrm{Ca}_{2} \mathrm{NiOsO}_{6}$ as calculated in three different schemes, $\mathrm{GGA}$, $\mathrm{GGA}+\mathrm{U}$, and $\mathrm{GGA}+\mathrm{U}+\mathrm{SOC}$. While both the compounds are predicted to be half-metal with zero density of states in the majority spin channel, and finite density of states in the minority spin channel due to nominal $\mathrm{d}^{2}$ occupancy of Os(VI) ion within GGA and GGA+U, inclusion of spin-orbit (SO) coupling induces $O \mathrm{~S}_{2 \mathrm{~g}}$ states spin-splitting, thereby opening a gap also in the minority spin channel.
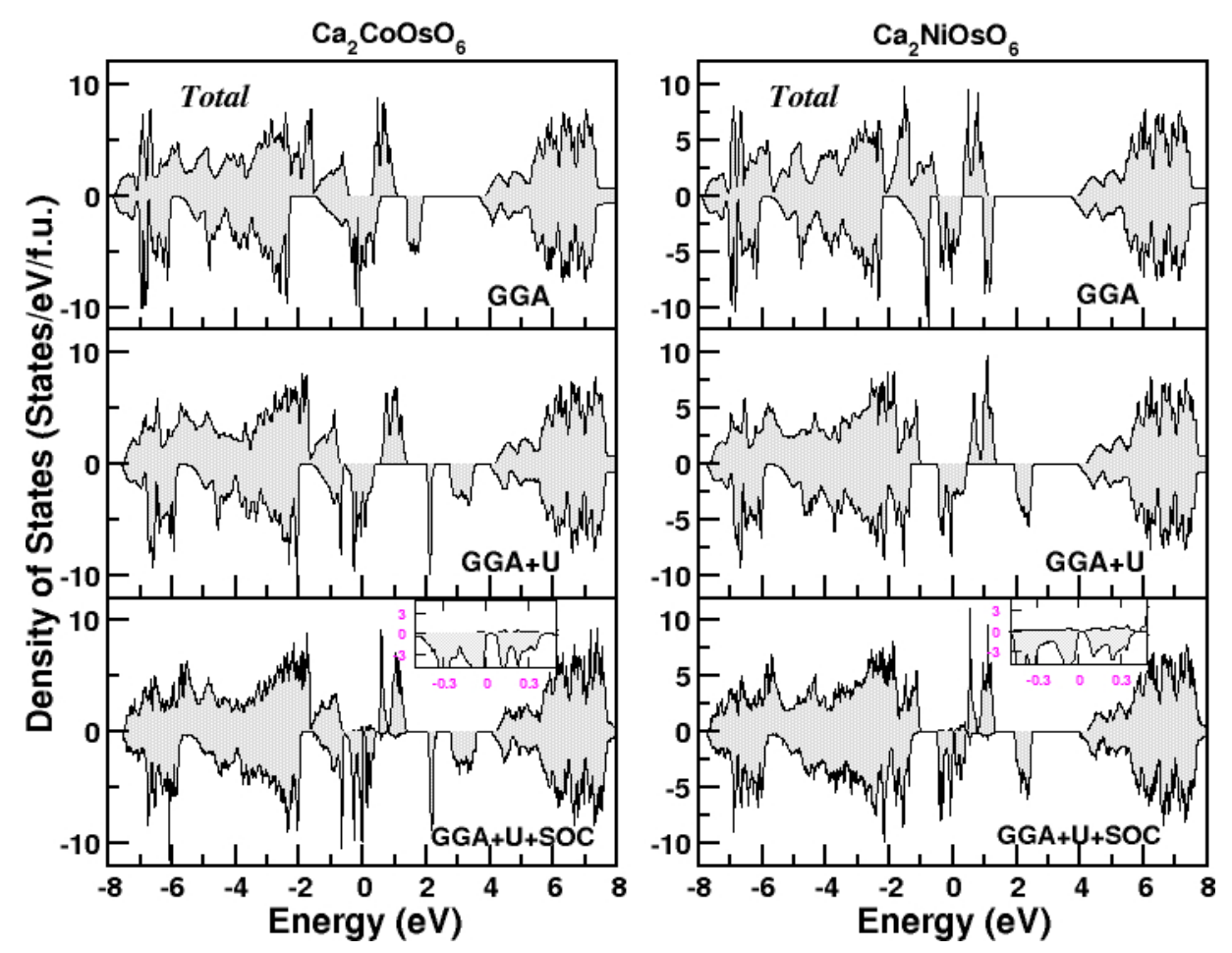

Figure S2 - Total density of states of $\mathrm{Ca}_{2} \mathrm{CoOsO}_{6}$ and $\mathrm{Ca}_{2} \mathrm{NiOsO}_{6}$ as calculated in GGA, GGA+U and GGA+U+SOC. The zero of the energy in each panel is set at the corresponding Fermi energy. The insets in the bottom panels show the density of states close to the Fermi energy. 
Figure $\mathrm{S} 3$, shows the $\mathrm{GGA}, \mathrm{GGA}+\mathrm{U}$ and $\mathrm{GGA}+\mathrm{U}+\mathrm{SO}$ density of states for $\mathrm{Ca}_{2} \mathrm{CoOsO}_{6}$ and $\mathrm{Ca}_{2} \mathrm{NiOsO}_{6}$ projected onto the $\mathrm{Co} / \mathrm{Ni}$ and $\mathrm{Os} d$ states. A close up view of the region near $\mathrm{E}_{\mathrm{F}}$ in the inset shows the energy gap that forms between filled and unfilled Os $\mathrm{t}_{2 \mathrm{~g}}$ states.
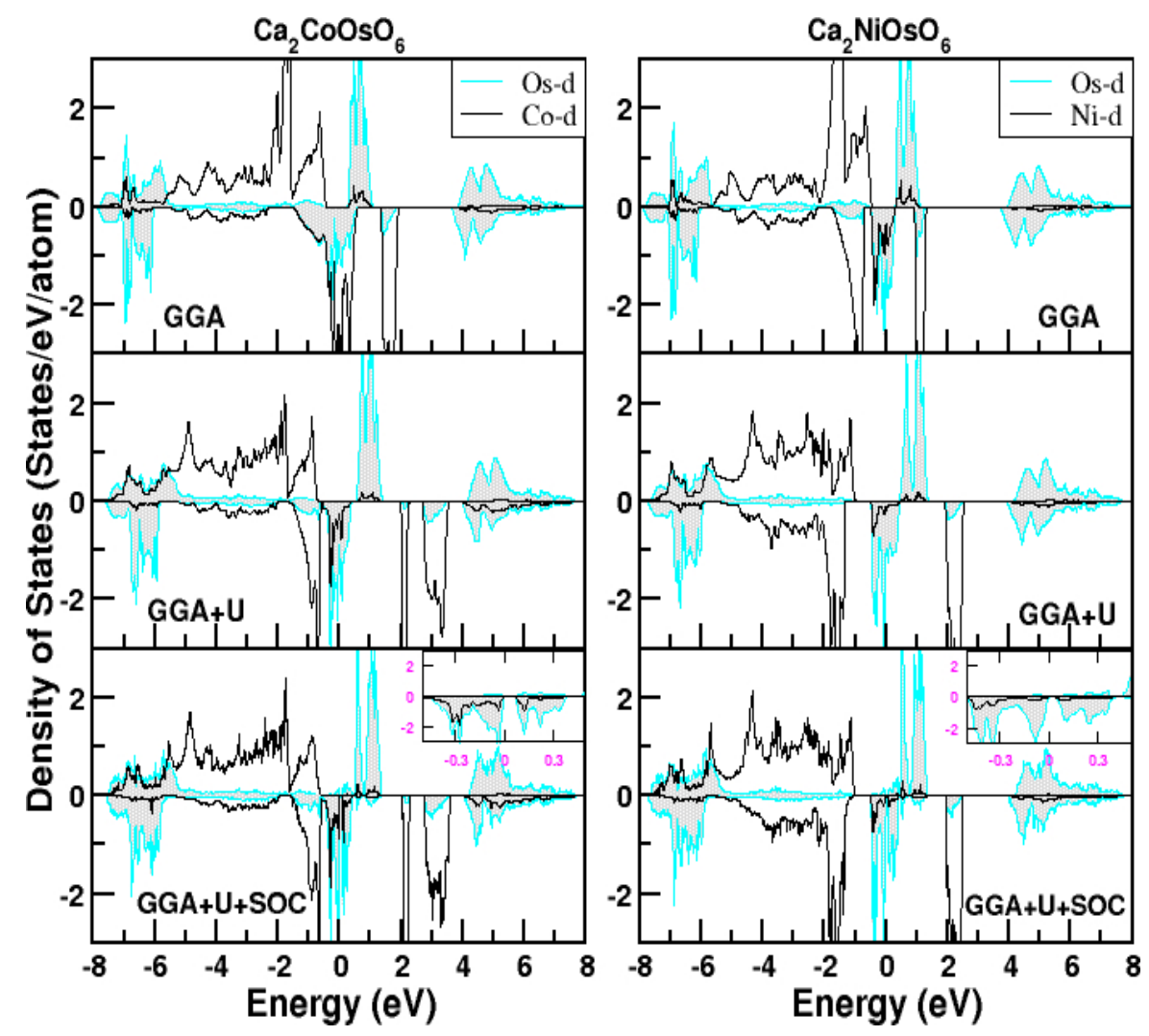

Figure $\mathrm{S3}$ - Density of states of $\mathrm{Ca}_{2} \mathrm{CoOsO}_{6}$ and $\mathrm{Ca}_{2} \mathrm{NiOsO}_{6}$ projected onto the $\mathrm{Co} / \mathrm{Ni}$ and Os-d states, as calculated in $\mathrm{GGA}$, $\mathrm{GGA}+\mathrm{U}$ and GGA+U+SOC. The zero of the energy in each panel is set at the corresponding Fermi energy. The insets in the bottom panels show the density of states close to the Fermi energy. 
Absolute values of the spin and orbital moments for each ion as obtained from the X-ray magnetic circular dichroism through application of the sum rules are given in Table S3.

Table S3: The spin $\left(m_{s}\right)$ and orbital $\left(m_{l}\right)$ moments obtained from X-ray magnetic circular dichroism measurements.

\begin{tabular}{|c|c|c|c|c|}
\hline & \multicolumn{2}{|c|}{$\mathrm{Ca}_{2} \mathrm{CoOsO}_{6}$} & \multicolumn{2}{c|}{$\mathrm{Ca}_{2} \mathrm{NiOsO}_{6}$} \\
\hline & $\mathrm{Co}$ & $\mathrm{Os}$ & $\mathrm{Ni}$ & $\mathrm{Os}$ \\
\hline$m_{\mathrm{s}}$ & +1.8 & -1.97 & +0.9 & -1.20 \\
\hline$m_{\mathrm{l}}$ & +0.8 & +0.56 & +0.27 & +0.34 \\
\hline$m_{\text {tot }}$ & +2.6 & -1.41 & +1.17 & -0.86 \\
\hline$m_{1} / m_{\mathrm{s}}$ & $44 \%$ & $-29 \%$ & $29 \%$ & $-28 \%$ \\
\hline
\end{tabular}


Figure S4 shows the overlap of two Os xy Wannier functions, obtained by massive downfolding procedure of integrating everything else other than Os $t_{2 g}-s$, placed at diagonal positions. The central part of the Wannier function follows the $x y$ symmetry while the tails are shaped according to the integrated out orbitals that has significant mixing with Os xy. We find presence of pronounced tails shaped according to $\mathrm{O}$ p orbitals due to strong Os-O covalency. These tails are found to bend towards $\mathrm{Ca}$ atom situated at the center of the square formed by Os-O-Co arms indicating Ca-O covalency to be also important in transmitting the Os-Os diagonal hopping. We however find little or no weight at Co site, thus failing to find evidence of effect of magnetic ion in the system in mediating the Os-Os hopping.

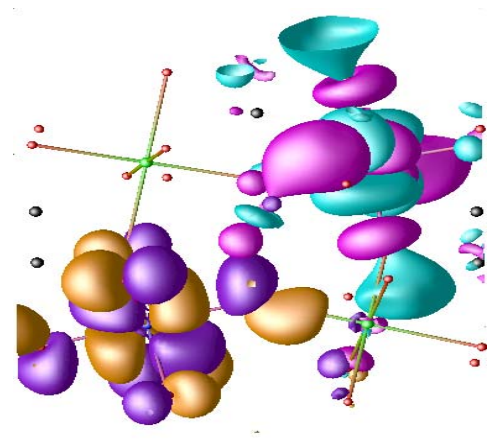

Figure S4 - Overlap of the Os xy effective Wannier functions in $\mathrm{Ca}_{2} \mathrm{CoOsO}_{6}$ obtained from NMTO-downfolding calculations, keeping active only the Os $t_{2 g}$ states in the basis. The plot shows the overlap of Wannier functions at two Os sites connected through diagonal hopping. Plotted are the orbital shapes (constant-amplitude surfaces) with the lobes of opposite signs labeled by cyan (violet) and magenta (golden) at two different Os sites. The red, small and green, medium balls denote the positions of the $\mathrm{O}$ and $\mathrm{Co}$. The $\mathrm{Ca}$ atom sits in the middle of the square, covered by the lobes of the Wannier functions. 


\section{REFERENCES}

1) Lopez, C. A.; Saleta, M. E.; Curiale, J.; Sanchez, R. D. Mater. Res. Bull. 2012, 47, 1158-1163.

2) Viola, M. C; Martinez-Lope, M. J.; Alonso, J. A.; De Paoli, J. M.; Pagola, S.; Pedregosa, J. C.; Fernandez-Diaz, M. T.; Carbonio, R. E. Chem. Mater. 2003, 15, 1655-1663.

3) Martínez-Lope, M. J.; Alonso, J. A.; Casais, M. T.; Fernandez-Díaz, M. T. Zeitschrift Für Naturforsch B 2003, 58, 127132.

4) Blum, C.G.F.; Holcombe, A.; Gellesch, M.; Rodan, S.; Morrow, R.; Maljuk, A.; Woodward, P.; Morris, P.; Wolter, A.U.B.; Büchner, B.; Wurmehl, S. J. Cryst. Growth 2015, 421, 39-44.

5) Chakraborty, K. R.; Das, A.; Krishna, P. S. R.; Yusuf, S. M.; Patwe, S. J.; Achary, S. N.; Tyagi. A. K. J. Alloy Compd. 2008, 457, 15-18.

6) Stitzer, K. E.; Smith, M. D.; zur Loye, H. C. Solid State Sci. 2002, 4, 311-316.

7) Steele, A. J.; Baker, P. J.; Lancaster, T.; Pratt, F. L.; Franke, I.; Ghannadzadeh, S.; Goddard, P. A.; Hayes, W.; Prabhakaran, D.; Blundell. S. J. Phys. Rev. B 2011, 84, 144416.

8) Erickson, A. S.; Misra, S.; Miller, G. J.; Gupta, R. R.; Schlesinger, Z.; Harrison, W. A.; Kim, J. M.; Fisher, I. R. Phys. Rev. Lett. 2007, 99, 016404.

9) Thompson, C. M.; Carlo, J. P.; Flacau, R.; Aharen, T.; Leahy, I. A.; Pollichemi, J. R.; Munsie, T. J. S.; Medina, T.; Luke, G. M.; Munevar, J.; Cheung, S.; Goko, T.; Uemura, Y. J.; Greedan, J. E. J. Phys.: Condens. Matter 2014, 26, 306003.

10) Feng, H. L.; Shi, Y.; Guo, Y.; Li, J.; Sato, A.; Sun, Y.; Wang, X.; Yu, S.; Sathish, C. I.; Yamaura, K. J. Solid State Chem. 2013, 201, 186-190.

11) Angelina, S.; Adler, P.; Schnelle, W.; Mikhailova, D.; Felser, C.; Tjeng, L. H.; Jansen. M. Z. Anorg. Allg. Chem. 2015, 641, 769-771.

12) Yuan, Y.; Feng, H. L.; Ghimire, M. P.; Matsushita,Y.; Tsujimoto, Y.; He, J.; Tanaka, M.; Katsuya, Y.; Yamaura., K. Inorg. Chem. 2015, 54, 3422-3431.

13) Kermarrec, E.; Marjerrison, C. A.; Thompson, C. M.; Maharaj, D. D.; Levin, K.; Kroeker, S.; Granroth, G. E.; Flacau, R.; Yamani, Z.; Greedan, J. E.; Gaulin, B. D. Phys. Rev. B 2015, 91, 075133.

14) Taylor, A. E.; Morrow, R.; Singh, D. J.; Calder, S.; Lumsden, M. D.; Woodward, P. M.; Christianson, A. D. Phys Rev $B$ 2015, 91, R100406.

15) Paul, A. K.; Sarapulova, A.; Adler, P.; Reehuis, M.; Kanungo, S.; Mikhailova, D.; Schnelle, W.; Hu, Z.; Kuo, C.; Siruguri, V.; Rayaprol, S.; Soo, Y.; Yan, B.; Felser, C.; Hao Tjeng, L.; Jansen, M. Z. Anorg. Allg. Chem. 2015, 641, 197. 